\title{
ОЦЕНКА РОЛИ МЕДИЦИНСКИХ ОШИБОК В СУДЕБНО-МЕДИЦИНСКИХ ЭКСПЕРТИЗАХ ЗА ПЕРИОД 2009-2019 ГГ.
}

\section{ASSESSMENT OF THE ROLE OF MEDICAL ERRORS IN FORENSIC EXAMINATIONS FOR THE PERIOD 2009-2019}

S. Moshenskaya M. Savelyeva

Summary. Medical errors are a serious public health problem. By recognizing the adverse events that occur, learning from them, and working to prevent them, you can improve patient safety. The topic of patient safety is of scientific interest, and not only in the narrow professional environment of clinical doctors, but also specialists of related specialties, for example, forensic medical experts involved in the production of examinations in medical cases. The article analyzes the commission forensic medical examinations (CME) conducted by the authors of this article for the period 2009-2019. The structure of the CME commission is dominated by deceased patients, and by gender composition - women. The age structure of the SME commission structure is relatively young, with children accounting for $25 \%$. It was revealed that in the structure of all SMEs conducted over a 10-year period, medical examinations predominate (68\%). The frequency of medical errors proved by the CME was $24 \%$. Thus, the development of a strategy aimed at preventing harm to patients can lead to significant improvements in medical care and significant savings in health systems.

Keywords: medical errors, defects in the provision of medical care, commission forensic medical examination.

\section{Актуальность}

$\mathbf{M}$ едицинские ошибки являются серьезной проблемой общественного здравоохранения, что связано с трудностью выявления причин ошибок и, даже если они найдены, с обеспечением согласованного жизнеспособного их решения, минимизирующего вероятность повторения неблагоприятных событий. Распознавая происходящие неблагоприятные события, учась на них и работая над их предотвращением, можно повысить безопасность пациентов и качество медицинской помощи [1]. Медицинские организации должны создать культуру безопасности, которая фоку-
Мошенская Светлана Петровна

К.м.н., врач - судебно-медицинский эксперт, ГБУз «Бюро судебно-медицинской экспертизы» Департамента здравоохранения города Москвы tsp-12@list.ru

Савельева Марина Ивановна Д.м.н., профессор, ФГБОУ ДПО РМАНПО Минздрава

Pоссии, Москва

marinasavelyeva@mail.ru

Аннотация. Медицинские ошибки являются серьезной проблемой общественного здравоохранения. Распознавая происходящие неблагоприятные события, учась на них и работая над их предотвращением, можно повысить безопасность пациентов. Тема безопасности пациентов представляет научный интерес, причем не только в узкой профессиональной среде клинических врачей, но и специалистов смежных специальностей, например, судебно-медицинских экспертов, участвующих в производстве экспертиз по медицинским делам. В статье проанализированы комиссионные судебно-медицинские экспертизы (СМЭ), проведенные авторами данной статьи за период 2009-2019 гг. В структуре комиссионных СМЭ преобладают умершие пациенты, а по половому составу 一 женщины. Возрастной состав структуры комиссионных СМЭ относительно молодой, дети составили $25 \%$. Выявлено, что в структуре всех СМЭ, проведенных за 10-ти летний период, преобладают экспертизы по медицинским делам (68\%). Частота встречаемости медицинских ошибок, доказанных проведением СМЭ составила 24\%. Таким образом, разработка стратегии, направленной на предотвращение вреда для пациентов, может привести к значительному улучшению медицинского обслуживания и значительной экономии средств систем здравоохранения.

Ключевые слова: медицинские ошибки, дефекты оказания медицинской помощи, комиссионная судебно-медицинская экспертиза.

сируется на совершенствовании системы, рассматривая медицинские ошибки как проблемы, которые необходимо преодолеть. Весь медицинский персонал должен сыграть свою роль в обеспечении безопасности медицинского обслуживания, как пациентов, так и медицинских работников [2].

Один из самых сложных вопросов современной системы здравоохранения: «Что является медицинской ошибкой?»,- остается без четко определенного ответа. Из-за нечетких определений в терминологии «медицинские ошибки» ее трудно измерить с научной точки зрения. Отсутствие стандартизированной номенклатуры 
и частично совпадающих определений медицинских ошибок затрудняет анализ, обобщение и оценку данных.

Существует два основных типа ошибок:

1. Ошибки бездействия, которые возникают в результате невыполненных действий. Примерами являются не привязывание пациента к инвалидной коляске или стабилизация каталки перед переносом пациента.

2. Ошибки, которые возникают в результате неправильных действий. Примеры включают введение лекарственного средства, на которое у пациента имеется известная аллергия, или отсутствие маркировки лабораторного образца, который впоследствии приписывают не тому пациенту.

Медицинские работники испытывают глубокие негативные психологические проблемы, такие как гнев, вина, неадекватность, депрессия и самоубийство из-за реальных или предполагаемых ошибок. К сожалению, отсутствие сообщений об ошибках повышает вероятность серьезного вреда для пациента. Во многих медицинских учреждениях действует жесткая политика, которая также создает неблагоприятную среду. Это может привести к тому, что персонал не решится сообщить об ошибке, свести к минимуму проблему или даже не сможет задокументировать проблему. Эти действия или их отсутствие могут способствовать развитию цикла медицинских ошибок. Когда эти ошибки обнаруживаются, они могут запятнать репутацию учреждения здравоохранения и его работников [3].

Некоторые эксперты считают, что термин «ошибка» является чрезмерно негативным, антагонистическим и увековечивает культуру вины. Профессионал, чья уверенность и моральный дух были подвергнуты сомнению в результате ошибки, может работать менее эффективно или даже может отказаться от продолжения медицинской карьеры. Многие эксперты предполагают, что термин «ошибка» не следует использовать вообще. Тем не менее, неблагоприятные исходы для пациента могут возникнуть именно из-за ошибок, поэтому исключить термин, скрывающий цель предотвращения и устранения его причин и следствий, не представляется возможным [4].

Ошибки, независимо от номенклатуры, обычно происходят из-за влияния множества факторов. Общественная и законодательная нетерпимость к медицинским ошибкам обычно иллюстрирует отсутствие понимания того, что некоторые ошибки, на самом деле, невозможно предотвратить с помощью современных технологий или ресурсов, доступных для практикующего врача. Человеческий фактор всегда является проблемой, и выявление ошибок позволяет предпринять стратегии улучшения.
В частности, обвинение или наказание отдельных лиц за ошибки, вызванные системными причинами, не устраняет причины и не предотвращает повторение ошибки.

Предотвратимые медицинские ошибки вносят существенный вклад в расходы на здравоохранение, включая более высокие расходы на медицинское страхование человека. Только медицинские работники, работающие вместе, смогут снизить затраты и трагические последствия, связанные с медицинскими ошибками. Так, например, Объединенная медицинская комиссия по безопасности пациентов представила несколько целей, которые смогли бы помочь учреждениям и практикующим врачам в создании более безопасной среды для пациентов и поставщиков медицинских услуг [5]. Цели Объединенной комиссии включают в себя: определение опасностей и рисков для безопасности пациентов; правильное идентифицирование пациентов, подтверждая личность, по крайней мере, двумя способами; улучшение коммуникации, например, быстрое получение результатов теста для конкретного пациента; предотвращение внутрибольничной инфекции с помощью мытья рук, применения антибиотиков после операции, смены катетера и мер предосторожности при постановке центральных катетеров; предотвращение ошибки в хирургии, удостоверившись, что правильная операция сделана на правильной части тела; пауза перед операцией для двойной проверки; использование устройств сигналов тревоги с возможностью убедиться, что сигналы тревоги на медицинском оборудовании услышаны и быстро проверены; использование лекарств правильно и безопасно, если дважды проверяется маркировка и правильно передаются лекарства пациенту или следующему поставщику; маркировка всех лекарств, даже тех, что в шприце, что предпочтительно делать в том месте, где готовятся лекарства; необходимо использовать дополнительное время с пациентами, которым были назначены антикоагулянты и химиотерапевтические агенты; чтобы предотвратить внутрибольничные инфекции, мытье рук должно быть обычным делом до и после посещения каждого пациента. Несмотря на то, что отдельные поставщики медицинских услуг должны нести ответственность за свои решения, растет понимание того, что большинство ошибок находятся вне контроля врача [6].

При этом по-прежнему сложно изменить культуру отсутствия документальной отчетности. Отказ сообщить об ошибках может привести к дисциплинарному взысканию клиницистов и повышению риска юридической ответственности. Вместо того чтобы обвинять, администраторы и наблюдательные советы медицинских организаций должны стремиться к устранению структуры дисциплинарных обвинений и позора и двигаться к структуре профилактики и образования. Эта культура включает в себя как усилия по обучению, так и самосо- 
вершенствованию, нацеленные на перепроектирование системы, и культуру отчетности, благодаря которой все поставщики медицинских услуг чувствуют себя в безопасности от возмездия и, следовательно, сообщают о проблемах безопасности, которые помогают постоянно улучшать уход за пациентами и повышать безопасность системы [7].

Итак, оценка и суждение человека могут включать ошибки, которые могут привести к катастрофическим последствиям. Однако в области медицины и здравоохранения наблюдается медленный прогресс в направлении серьезных изменений в безопасности. Здравоохранение отстает от других специализированных отраслей, таких как авиация и атомная энергетика, где значительно улучшена общая безопасность, особенно в снижении риска ошибок. После нескольких громких случаев заболевания, связанного с медицинскими ошибками, в США в 1990-х годах был опубликован отчет под названием «Человеку свойственно ошибаться: построение более безопасной системы здравоохранения» [8]. В отчете было представлено, что в США ежегодно от 50 до 100 тысяч пациентов могут умереть в результате врачебных ошибок.

В медицинском сообществе наблюдается повышенная осведомленность о безопасности пациентов это стало основным приоритетом. Акцент сместился с распределения вины медицинского персонала на предотвращение ошибок и внедрение механизмов обеспечения безопасности пациентов при оказании медицинской помощи. Тип ошибок можно разделить на ошибки из-за действий и ошибок из-за знаний или планирования. В здравоохранении существует несколько факторов, которые могут влиять на побочные эффекты и безопасность пациента. Хотя технология может повысить безопасность пациентов, она также вводит новые источники ошибок. Умение работать с людьми позволяет увеличить безопасность. Было показано, что командная работа оказывает благотворное влияние на безопасность пациентов [8].

По данным журнала British Medical Journal [9] приблизительно один из 20 (6\%) пациентов при оказании медицинской помощи страдает от врачебной ошибки, которой можно было избежать. У $12 \%$ из этих пациентов развивается пожизненная инвалидность или наступает смерть. Наибольшее количество таких врачебных ошибок связано с применением медицинских препаратов и инвазивных процедур, и чаще это происходит в отделениях хирургии и интенсивной терапии, чем в отделениях общего профиля. По данным группы исследователей под руководством M. Panagioti из Манчестерского университета, включающих 70 наблюдательных исследований с участием 337025 преимущественно взрослых пациентов, оценена распространенность предотвратимого вреда для пациентов в различных медицинских учреждениях, включая больницы и учреждения первичной медицинской помощи. Они также исследовали степень тяжести и наиболее распространенные виды предотвратимого вреда для пациентов. Так выявлено, что при лечении 28150 пациентов были допущены опасные врачебные ошибки, а 15419 пациентам был нанесен предотвратимый вред. В 12\% случаев был нанесен серьезный предотвратимый вред (вызывающий длительную, пожизненную инвалидность или смерть). В 23\% случаев он был связан с хирургическим вмешательством, в 16\% случаев имело место инфицирование пациентов, 49\% были связаны с применением лекарств или других методов. По сравнению с больницами общего профиля предотвратимый вред был более распространенным в отделениях хирургической и интенсивной терапии, а реже всего такие случаи происходили в акушерских отделениях [9].

В обзорном исследовании Shah R.K. с соавторами [10], в котором использовался анонимный онлайн-опрос среди членов Американской академии отоларингологии и хирургии головы и шеи (AAO-HNS), было показано, что из 681 респондента 445 (66\%) сообщили о событии за последние 6 месяцев, из которых было отобрано для последующего анализа 222 сообщения. Средний

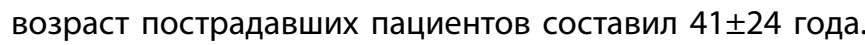
Неблагоприятные последствия имели место более чем в половине случаев, а корректирующие меры были приняты в $82,8 \%$ случаев. Из опрошенных $68 \%$ врачей впоследствии изменили свою практику. Домены с наибольшим количеством зарегистрированных ошибок были техническими (27,9\% от всех событий, $71 \%$ с большой заболеваемостью), административными (12,2\%, 3,7\% соответственно), диагностическими тестами $(10,8 \%, 8,3 \%$ соответственно) и хирургическим планированием (9,9\%, $45,5 \%$ соответственно). Было выявлено 8 операций в неправильном месте, 23 повреждения черепных нервов (91,3\% основных заболеваний) и 9 ошибок во время эндоскопической операции на пазухах (55,6\% основных заболеваний). Было зафиксировано 4 смерти. Исследователи сделали вывод о том, что отоларингологи остаются уязвимыми к ошибкам и связанным с ними нежелательным явлениям. Домены с наибольшим риском серьезных заболеваний, связанных с ошибками, мало изменились за 10-ти летний период и включают ошибки в техническом, административном, диагностическом тестировании, хирургическом планировании и хирургическом оборудовании. Осведомленность о зонах повышенного риска может помочь сосредоточить профилактические усилия в этих областях [10].

Таким образом, тема безопасности пациентов в различных областях медицины и здравоохранения пред- 
Таблица 1. Сводные данные по СМЭ за 2009-2019 гг.

\begin{tabular}{|c|c|c|c|c|c|c|c|c|c|}
\hline Год & $\begin{array}{l}\text { Кол-во } \\
\text { СМэ } \\
\text { (n/\%) }\end{array}$ & $\begin{array}{l}\text { Мужч. } \\
\text { (n/\%) }\end{array}$ & $\begin{array}{l}\text { Женщ. } \\
\text { (n/\%) }\end{array}$ & $\begin{array}{l}\text { Живые } \\
\text { (n/\%) }\end{array}$ & $\begin{array}{l}\text { Умершие } \\
\text { (n/\%) }\end{array}$ & $\begin{array}{l}\text { Вскрытие } \\
\text { было (n/\%) }\end{array}$ & $\begin{array}{l}\text { Вскрытия } \\
\text { не было } \\
\text { (n/\%) }\end{array}$ & $\begin{array}{l}\text { Мед. } \\
\text { ошибки } \\
\text { есть } \\
\text { (n/\%) }\end{array}$ & $\begin{array}{l}\text { Отриц. } \\
\text { юр. исход } \\
\text { (n/\%) }\end{array}$ \\
\hline 2009 & $4 / 0,98$ & $1 / 0,7$ & $3 / 1,13$ & $1 / 0,64$ & $3 / 1,19$ & $2 / 1,21$ & $2 / 0,82$ & $1 / 1,14$ & $1 / 1,79$ \\
\hline 2010 & $20 / 4,89$ & $14 / 9,8$ & $6 / 2,26$ & $12 / 7,69$ & $8 / 3,16$ & $12 / 7,27$ & $8 / 3,28$ & $4 / 4,55$ & $4 / 7,14$ \\
\hline 2011 & $109 / 26,7$ & $14 / 9,8$ & $95 / 35,7$ & $15 / 9,62$ & $94 / 37,2$ & $15 / 9,09$ & $94 / 38,5$ & $10 / 11,4$ & $4 / 7,14$ \\
\hline 2012 & \begin{tabular}{|l|}
$41 / 10,02$ \\
\end{tabular} & $13 / 9,09$ & $28 / 10,5$ & \begin{tabular}{|l|}
$19 / 12,2$ \\
\end{tabular} & $22 / 8,7$ & $19 / 11,5$ & $22 / 9,02$ & $12 / 13,6$ & $5 / 8,93$ \\
\hline 2013 & $19 / 4,65$ & $8 / 5,59$ & $11 / 4,14$ & $8 / 5,13$ & $11 / 4,35$ & $13 / 7,87$ & $6 / 2,46$ & $4 / 4,55$ & $2 / 3,57$ \\
\hline 2014 & $46 / 11,25$ & $16 / 11,2$ & $30 / 11,3$ & $25 / 16,0$ & $21 / 8,3$ & $25 / 15,2$ & $21 / 8,61$ & $15 / 17,1$ & $10 / 17,9$ \\
\hline 2015 & $34 / 8,31$ & $18 / 12,6$ & $16 / 6,02$ & $18 / 11,5$ & $16 / 6,32$ & $18 / 10,9$ & $16 / 6,56$ & $7 / 7,95$ & $3 / 5,36$ \\
\hline 2016 & $24 / 5,87$ & $13 / 9,09$ & $11 / 4,14$ & $11 / 7,05$ & $13 / 5,14$ & $11 / 6,67$ & $13 / 5,33$ & $4 / 4,55$ & $13 / 23,2$ \\
\hline 2017 & $35 / 8,56$ & $16 / 11,2$ & $19 / 7,14$ & $13 / 8,33$ & $22 / 8,7$ & $14 / 8,48$ & $21 / 8,61$ & $7 / 7,95$ & $6 / 10,71$ \\
\hline 2018 & $40 / 9,78$ & $15 / 10,5$ & $25 / 9,4$ & $19 / 12,2$ & $21 / 8,3$ & $21 / 12,7$ & $19 / 7,79$ & $10 / 11,4$ & $8 / 14,29$ \\
\hline 2019 & $37 / 9,05$ & $15 / 10,5$ & $22 / 8,27$ & $15 / 9,62$ & $22 / 8,7$ & $15 / 9,09$ & $22 / 9,02$ & $14 / 15,9$ & $9 / 16,07$ \\
\hline Итого & $409 / 100$ & $143 / 100$ & $266 / 100$ & $156 / 100$ & $253 / 100$ & $165 / 100$ & $244 / 100$ & $88 / 100$ & $56 / 100$ \\
\hline
\end{tabular}

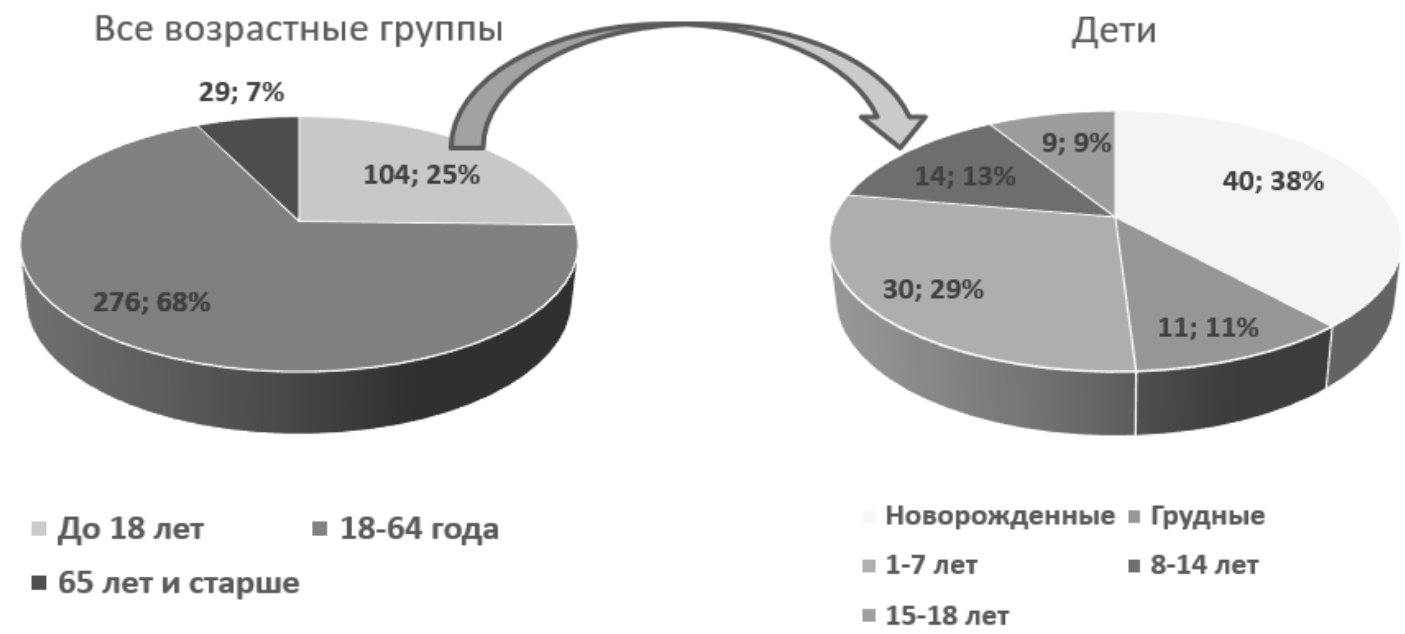

Рис. 1. Структура возрастных групп по всем СМЭ за период 2009-2019 гг.

ставляет научный интерес, причем не только в узкой профессиональной среде врачей различных специальностей причем как хирургических так и терапевтических, но и специалистов смежных специальностей, например, судебно-медицинских экспертов, участвующих в производстве экспертиз по медицинским делам.

\section{Lель исслеАования}

Исследование судебно-медицинских экспертиз по уголовным и гражданским делам связанным с правонарушениями медицинских работников за 10-ти летний период с анализом причин и поиском путей профилактики их развития для построения системы защиты профессиональной медицинской деятельности в Российской Федерации.

\section{ЗаАачи исслеАования}

Выявить распространенность и динамику СМЭ по уголовным и гражданским делам связанным с правонарушениями медицинских работников среди насильственных и ненасильственных смертей по всем СМЭ, проведенным за период 2099-2019 гг.;

Определить структуру медицинских ошибок в рамках судебно-медицинской практики;

Проанализировать причины, приводящие к ошибкам в профессиональной медицинской деятельности;

Провести анализ медицинских дефектов оказания МП в рамках сложных СМЭ, связанных с применением ЛС. 


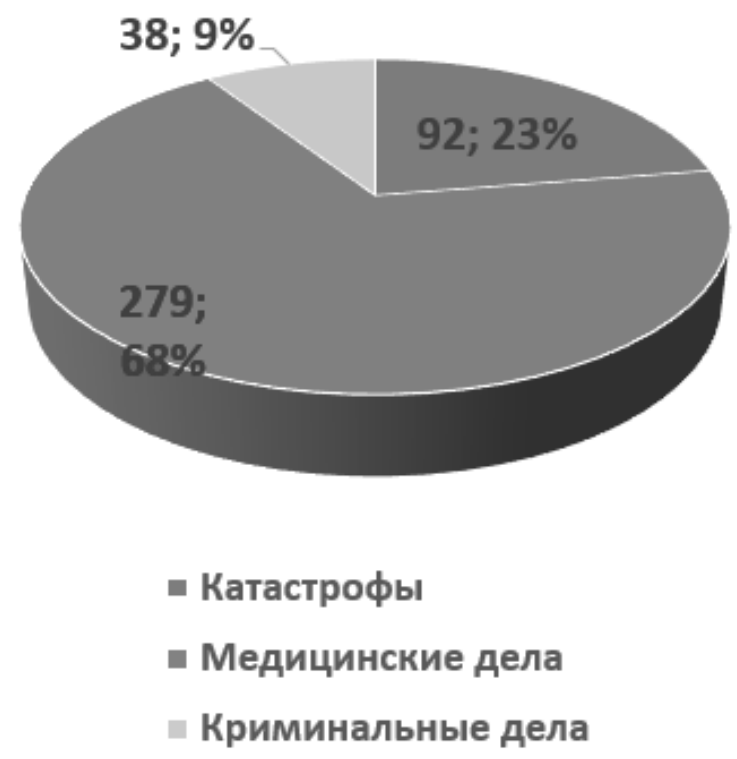

Рис. 2. Структура всех СМЭ, проведенных за период 2009-2019 гг. (n=409).

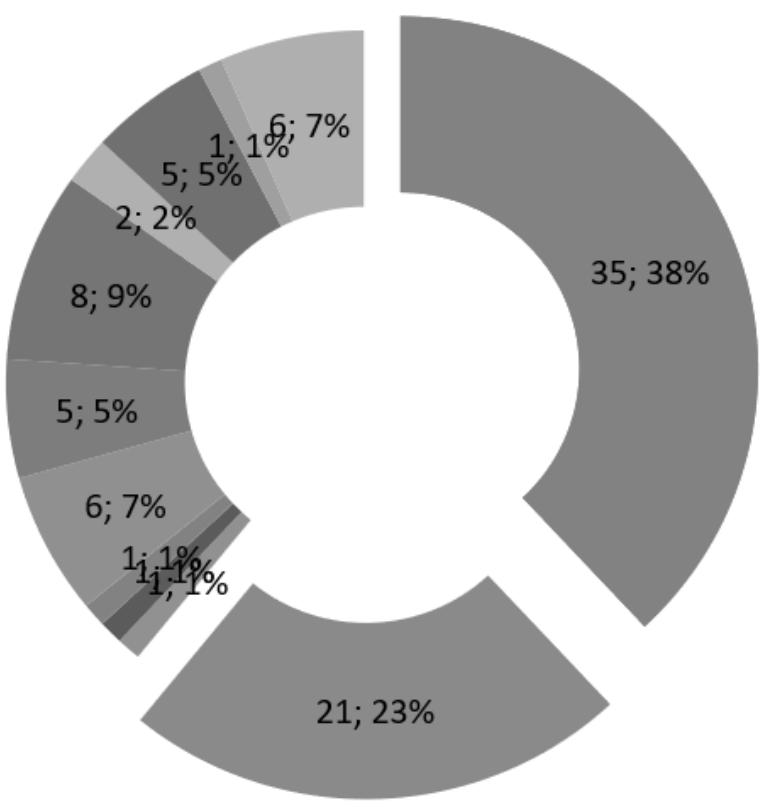

П Осуждены врачи

Материальная компенсация

УД доследуется

п Обвинительное (врач в бегах)

ш иске отказано

прачи оправданы

ш УД прекращено за отсут. Состава преступления

ш УД прекращено по сроку давности

УД закрыто в связи с отс-м конкретного лица

Рис. 3. Анализ известных юридических исходов по медицинским делам СМЭ за 2009-2019 гг. (n=86).

\section{Материалы и метолы исслеАования}

Проведен ретроспективный анализ сложных судебно-медицинских экспертиз, проведенных авторами за период 2009-2019 гг. Статистическая обработка полученных данных проводилась с использованием программы Statistica 10.0 (StatSoft, Inc). Использовались методы описательной статистики. Осуществляли проверку нормальности распределения количественных призна- ков. Критическое значение уровня статистической значимости принимали равным 5\%.

\section{Результаты исслеАования}

Всего нами проанализировано 409 комиссионных судебно-медицинских экспертиз (СМЭ) за период 20092019 гг. (10 лет), сводные данные которых представлены в таблице 1 в количественном и процентном выражении (n/\%). 


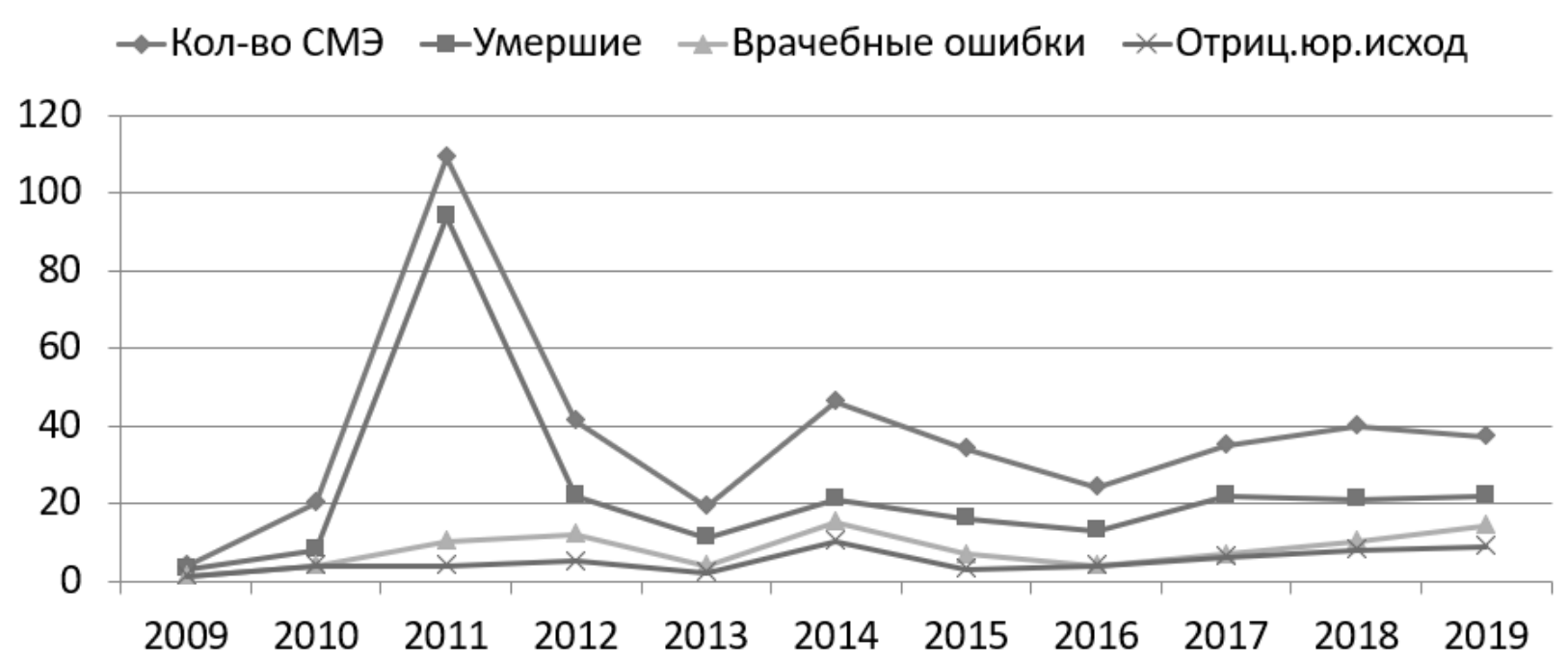

Рис. 4. Динамика СМЭ по общему количеству умерших, наличию связей с врачебными ошибками и отрицательным юридическим исходом (осуждение врачей и материальная компенсация) за 10 лет в абс. ч. $(n=409)$.

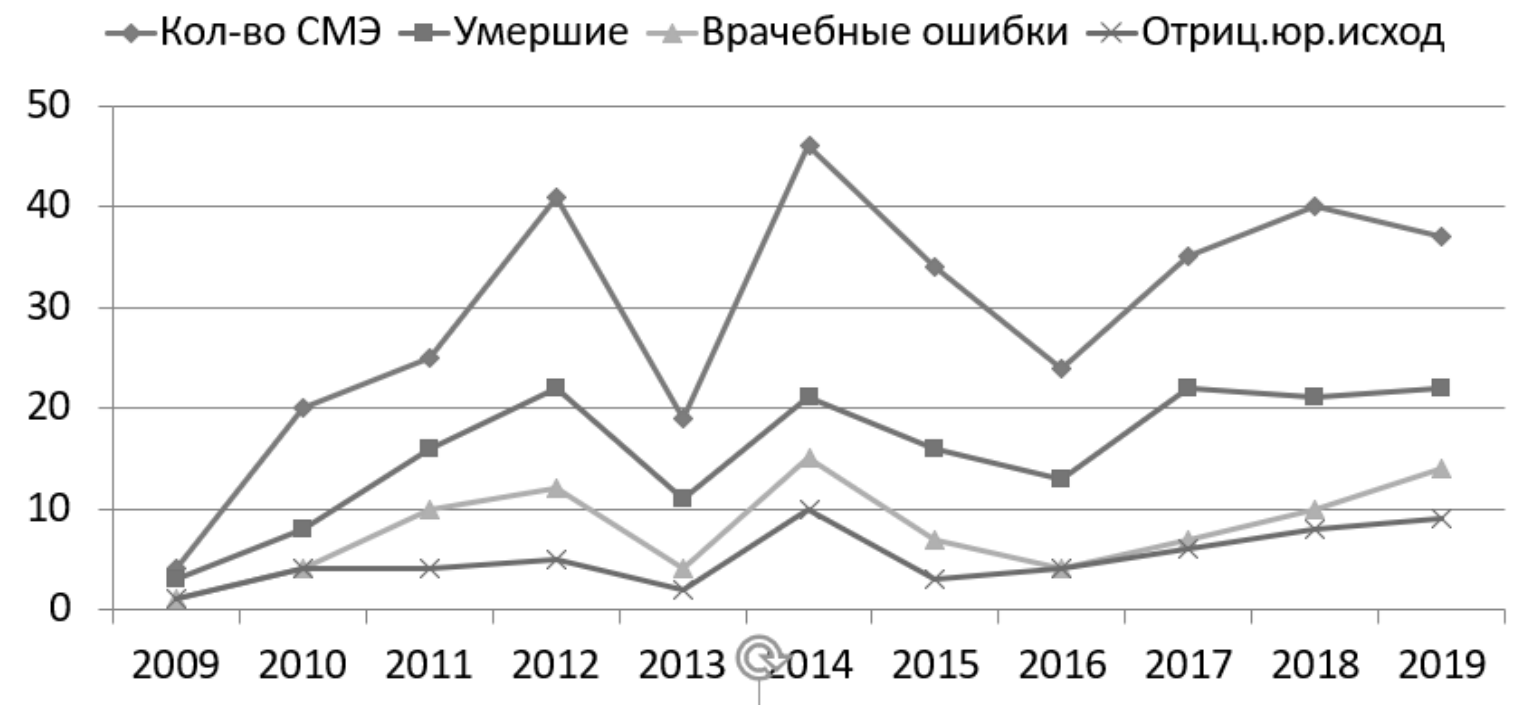

Рис. 5. Динамика СМЭ по общему количеству умерших, наличию связей с врачебными ошибками и отрицательным юридическим исходом (осуждение врачей и материальная компенсация) за 10 лет

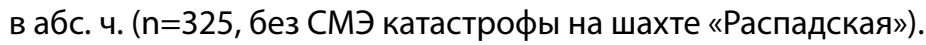

Сначала нами были определены общие характеристики по выборке $(n=409)$, а именно: возраст от 0 года до 85 лет; медиана возраста - 32 года; средний возраст $(\mathrm{M} \pm \mathrm{m}) 31,96 \pm 17,17$. Структура возрастных групп представлена на рисунке 1.

Распределение по полу было следующим: 35\% мужчин и 65\% женщин. Все СМЭ разделялись по живым (38\%) и умершим (62\%), а также по факту проведения патолого-анатомического или судебно-медицинского вскрытия: вскрытие проводилось в $60 \%$ случаев.
В структуре всех комиссионных СМЭ, проведенных за 10-ти летний период и представленной на рисунке 2, преобладают экспертизы по медицинским делам (68\%). На втором месте по распространенности идут СМЭ по идентификации личности после катастроф - в 23\% случаев, а на последнем - СМЭ по криминальным делам (убийства, самоубийства и др.) в 9\% случаев. Учитывая тот факт, что катастрофы в мирное время, как правило, носят случайный, но массовый характер, то доля СМЭ по медицинским делам может значительно увеличиться. Так в нашей выборке СМЭ по идентификации лично- 


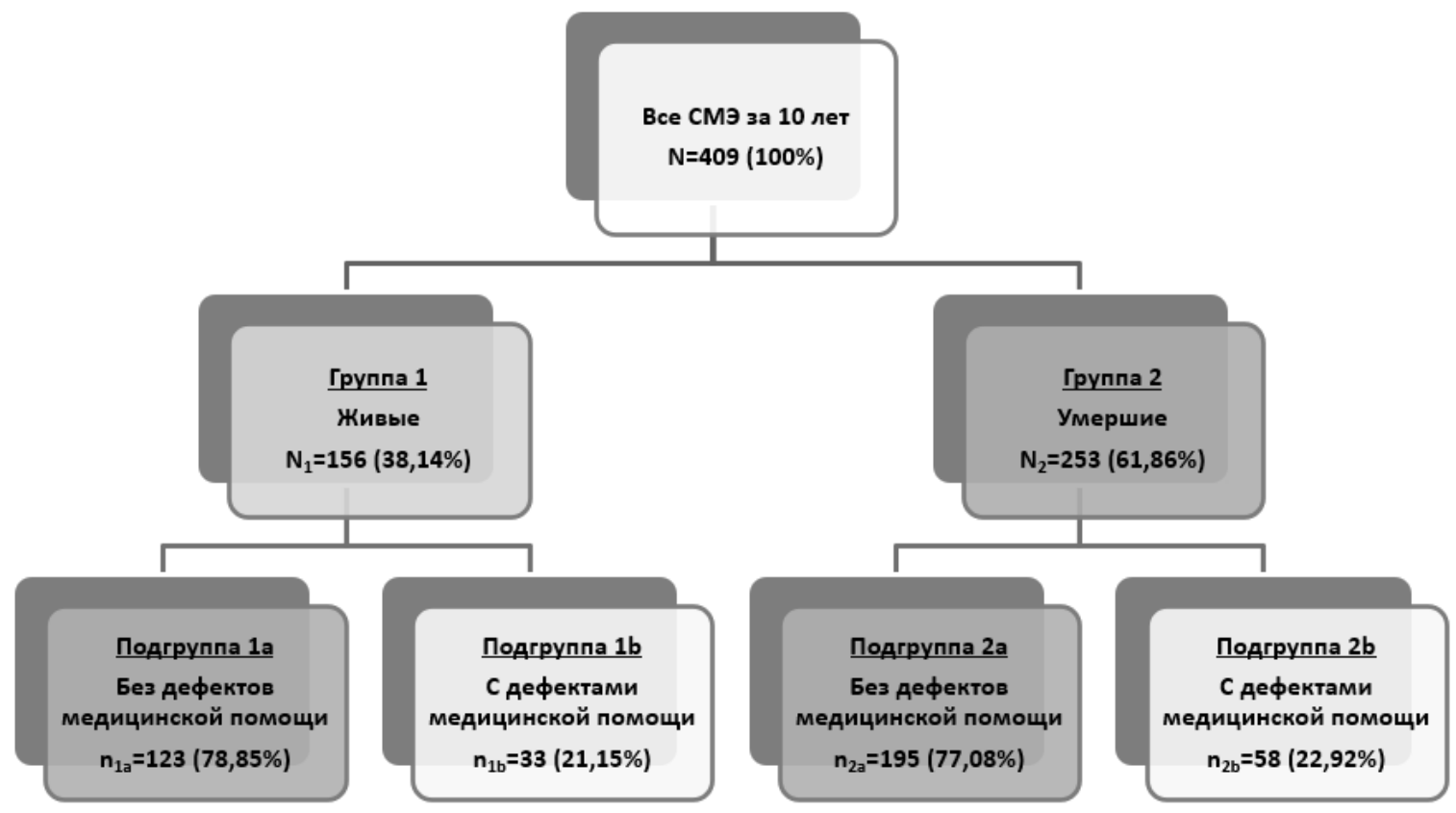

Рис. 6. Схема анализа всех СМЭ в группах и подгруппах.

\section{Группа 1 Живые ( $\mathrm{n=156)}$}

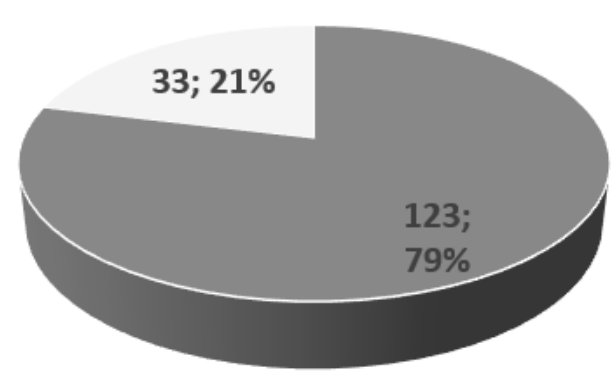

- Без дефектов оказания МП

С дефектами оказания МП

\section{Группа 2 \\ Умершие ( $n=253)$}

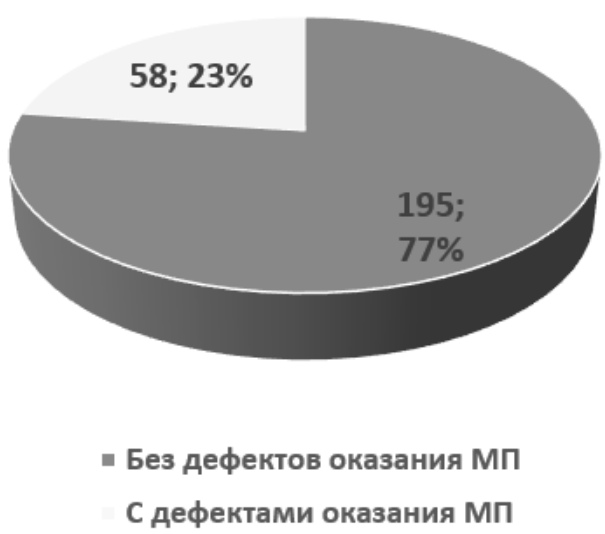

Рис. 7. Сравнение распространенности в подгруппах с и без дефектов оказания МП.

сти/оценке причин смерти у погибших $(\mathrm{n}=78)$ и оценке ущерба здоровью у выживших $(n=6)$ после катастрофы на шахте «Распадская», произошедшей в 2011 году, составили всего 84 экспертизы, а также 8 экспертиз погибших в авиакатастрофе в 2012 году, т.е. всего 92 СМЭ по катастрофам.

При анализе отдельной выборки по медицинским делам $(\mathrm{n}=279)$ нами обнаружено, что медицинские ошибки встречались в 24\% случаев ( $\mathrm{n}=68)$ против 76\% случаев ( $\mathrm{n}=211)$, когда медицинские ошибки в процессе проведения СМЭ не были доказаны. При этом только в $31 \%$ случаев были известны юридические исходы по гражданским и уголовным делам против 69\% случаев, когда данная информация оказалась недоступной для анализа. Однако мы детализировали известные юридические исходы и обнаружили (Рис. 3), что отрицательных юридических исходов, к которым относятся 


\section{Группа 1 - Живые}

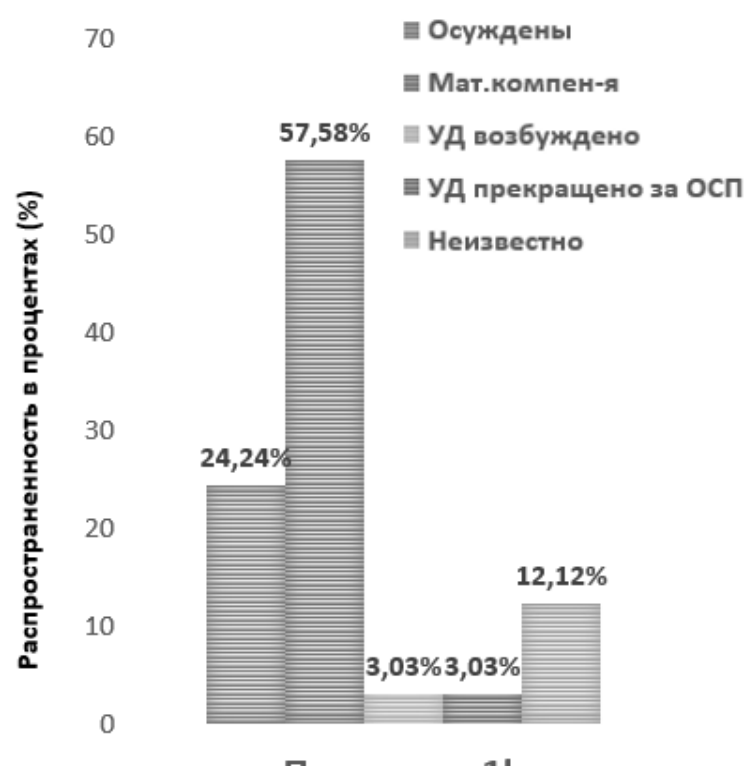

\section{Подгруппа 1b}

\section{Группа 2 - Умершие}

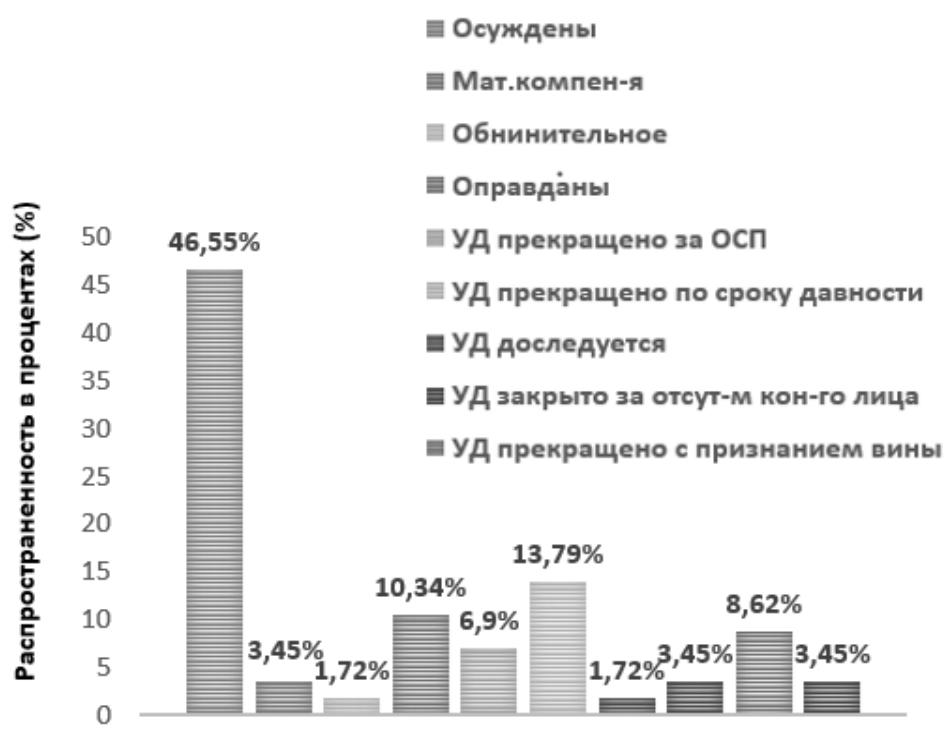

Подгруппа 2b

Рис. 8. Сравнение распространенности юридических исходов в подгруппах с дефектами оказания МП.

осуждение медицинских работников, в том числе обвинительное заключение суда (моральный ущерб), а также материальная компенсация (финансовый ущерб) за 10 -ти летний период составили $62 \%$, т.е. больше половины.

Далее нами проанализирована динамика СМЭ по общему количеству умерших, наличию связей с врачебными ошибками и отрицательным юридическим исходом (осуждение врачей и материальная компенсация) за 10 лет в абс. ч. (n=409) (Рис. 4).

При анализе обнаружено, что выраженной динамики роста числа СМЭ по умершим, числу врачебных ошибок и отрицательным юридическим исходам не отмечается, за исключением 2011 года в связи с проведением СМЭ по катастрофе на шахте «Распадская». Однако при проведении повторного анализа, но уже с исключением СМЭ по катастрофе на шахте «Распадская» (Рис. 5), нами было обнаружено, что при увеличении общего числа СМЭ по годам за 10-ти летний период отмечается незначительная динамика роста числа СМЭ по умершим и числу врачебных ошибок, но практически отсутствует динамика по отрицательным юридическим исходам.

Дальнейший анализ был проведен в двух группах (живых и умерших), в каждой из которых были выделены две подгруппы (без дефектов оказания медицинской помощи и с дефектами оказания медицинской помощи), представленных на рисунке 6. В результате оказалось, что среди всех СМЭ за 10-ти летний период преобладают экспертизы по умершим пациентам (группа 2), которые составляют $61,86 \%$, и что на 23,72\% больше, чем экспертиз по живым пациентам (группа 1).

При этом выявлено, что частота распространенности СМЭ с доказанными дефектами оказания медицинской помощи (МП) в группах живых и умерших практически не различается и составляет $21,15 \%$ и 22,92\% соответственно, а в преобладающем большинстве СМЭ за 10-ти летний период не обнаружены дефекты оказания МП (78,85\% и 77,08\% соответственно) (Рис. 7 ).

При сравнении юридических исходов в подгруппах с дефектами оказания МП двух групп - живых и умерших нами обнаружены различия, наглядно показанные на рисунке 8.

Распространенность всех отрицательных юридических исходов достоверно преобладает в подгруппе $1 \mathrm{~b}$ (живые) и составляет 81,82\%, что на $30,1 \%$ выше, чем в подгруппе 2b (умершие), для которой данный параметр составляет 51,72\%. Однако осужденных медиков на 22,31\% больше в подгруппе 2 b (46,55\% vs 24,24\%), а материальных компенсаций - наоборот больше на 54,13\% в подгруппе $1 \mathrm{~b}$ (57,58\% vs 3,45\%). Таким образом, более тяжелые юридические последствия в виде обвинительного приговора со сроками тюремного заключения связаны с более тяжелыми последствиями причинения вреда здоровью в виде смерти, и соответственно более легкие юридические последствия в виде материальной 
компенсации связаны с ущербом здоровью, не приведшим к летальному исходу в результате оказания медицинской помощи.

\section{Выво $\triangle \mathrm{b}$}

В возрастной структуре всех сложных СМЭ преобладает группа лиц среднего возраста $(67,48 \%)$, однако значительно представлена группа детей $(25,43 \%)$, среди которых доминируют новорожденные (40\%), а возрастная группа до 1 года жизни, включая и новорожденных, представлена в $51 \%$ случаев.

В структуре всех сложных СМЭ, проведенных за 10-ти летний период, преобладают экспертизы по медицинским делам (68\%); идентификация личности после катастроф составила 23\%, а СМЭ по насильственным действиям - 9\%.

Среди всех СМЭ за 10-ти летний период преобладают экспертизы по умершим пациентам (группа 2) и составляют $61,86 \%$ и что $23,72 \%$ больше, чем экспертиз по живым пациентам (группа 1). Частота распространенности СМЭ с доказанными дефектами оказания медицинской помощи (МП) в группах живых и умерших практически не различается и составляет $21,15 \%$ и 22,92\% соответ- ственно, а в преобладающем большинстве СМЭ за 10-ти летний период не обнаружены дефекты оказания МП (78,85\% и $77,08 \%$ соответственно).

Частота встречаемости врачебных ошибок, доказанных проведением СМЭ составила 24\%.

Отрицательные юридические исходы в виде осуждения врачей или материальной компенсации встречались всего в 65\% случаев среди всех известных юридических исходов. Распространенность отрицательных юридических исходов достоверно преобладает у живых пациентов с дефектами оказания МП и составляет $81,82 \%$, что на 30,1\% выше, чем у умерших пациентов с дефектами оказания МП, для которой данный параметр составляет 51,72\%. Однако осужденных медиков на 22,31\% оказалось больше у умерших с дефектами оказания МП (46,55\% vs 24,24\%), а материальных компенсаций - наоборот больше на 54,13\% у живых с дефектами оказания МП (57,58\% vs 3,45\%).

При увеличении общего числа СМЭ по годам за 10ти летний период отмечается незначительная динамика роста числа СМЭ по умершим и числу врачебных ошибок, но практически отсутствует динамика по отрицательным юридическим исходам.

\section{ЛИТЕРАТУРА}

1. Oyebode F. Clinical errors and medical negligence. Med Princ Pract. 2013;22(4):323-33. [PMC free article] [PubMed]

2. HeloS, Moulton CE. Complications: acknowledging, managing, and coping with human error. Transl Androl Urol. 2017 Aug;6(4):773-782. [PMC free article] [PubMed]

3. Robertson JJ, Long B. Suffering in Silence: Medical Error and its Impact on Health Care Providers. J Emerg Med. 2018 Apr;54(4):402-409. [PubMed]

4. Battard J. Nonpunitive response to errors fosters a just culture. Nurs Manage. 2017 Jan;48(1):53-55. [PubMed]

5. Mascioli S, Carrico CB. Spotlight on the 2016 National Patient Safety Goals for hospitals. Nursing. 2016 May;46(5):52-5. [PubMed]

6. Delacroix R. Exploring the experience of nurse practitioners who have committed medical errors: A phenomenological approach. J Am Assoc Nurse Pract. 2017 Jul;29(7):403-409. [PubMed]

7. Thomas L. Rodziewicz; John E. Hipskind. Medical Error Prevention [PubMed] Last Update: May 5, 2019. https://www.ncbi.nlm.nih.gov/books/NBK499956/

8. Danino J, Muzaffar J, Metcalfe C, Coulson C. Patient safety in otolaryngology: a descriptive review.Eur Arch Otorhinolaryngol. 2017 Mar;274(3):1317-1326. doi: 10.1007/s00405-016-4291-z. Epub 2016 Sep 13.

9. https://medportal.ru/mednovosti/news/2019/07/19/400harm/

(c) Мошенская Светлана Петровна ( tsp-12@list.ru), Савельева Марина Ивановна ( marinasavelyeva@mail.ru). Журнал «Современная наука: актуальные проблемы теории и практики» 